\title{
The association of change in serum cholesterol levels and clinical treatment response in patients with schizophrenia: a prospective, randomized and open-label study
}

\section{Yi-Lung Chen}

Taipei City Hospital Songde Branch

Chih-Chiang Chiu

Taipei City Hospital Songde Branch

Kun-Po Chen

Taipei City Hospital Songde Branch

Ming-Hong Tai

Sun Yat-Sen University

For-Wey Lung ( $\square$ forwey@seed.net.tw )

Calo Psychiatric Center https://orcid.org/0000-0002-4505-7583

Research article

Keywords: Paliperidone; Risperidone; Olanzapine; Lipid levels; Schizophrenia

Posted Date: August 13th, 2019

DOl: https://doi.org/10.21203/rs.2.12759/v1

License: (c) (i) This work is licensed under a Creative Commons Attribution 4.0 International License.

Read Full License 


\section{Abstract}

Background: In the past, it was suggested that dyslipidemia was associated with clinical improvement in patients with schizophrenia treated with antipsychotics; however, measurement at a single time point post-treatment, as done in most studies, could have contributed to the inconsistent results. The aim of this study was to investigate whether changes in serum levels of lipid and other covariates were associated with clinical response in patients with schizophrenia treated with atypical antipsychotics, using repeated measurements and considering time effects. Method: A total of 90 patients with schizophrenia were enrolled in this 12-week prospective, randomized and open label study. Positive and Negative Syndrome Scale (PANSS) score and a standard serum lipid profile were measured at baseline (day 0 ) and subsequently followed up at weeks 4,8 and 12. The generalized estimating equation (GEE) model was applied to examine the relationship between serum lipids and treatment response, controlling for other potential variables. Results: The results of GEE analysis showed that the increase in serum total cholesterol levels during 12 weeks' antipsychotic treatment was significantly associated with a reduction in PANSS total score $(\beta=-0.37, p=0.02)$ and positive symptom score $(\beta=-0.34, p=0.01)$ over time. Conclusions: These findings revealed that the change in serum total cholesterol level was positively associated with the therapeutic efficacy of atypical antipsychotics. Serum total cholesterol may be a potential predictor of clinical response in patients with schizophrenia treated with atypical antipsychotics. Trial Registration: ClinicalTrials.gov identifier: NCT03730857. The trial was retrospectively registered on 11 Feb, 2019.

\section{Introduction}

Schizophrenia is a severe mental illness causing considerable disability, and regular antipsychotic medication can help to alleviate the symptoms. Atypical antipsychotics have advantages over typical antipsychotics in schizophrenia treatment due to their low rate of adverse effects and potentially superior efficacy. However, there remain some issues to be addressed. Clinical use of antipsychotic drugs for the treatment of schizophrenia may be associated with weight gain, abnormal glucose metabolism, atherogenic lipid levels and increased risk of metabolic disorder [1-6]. A number of studies have reported that the therapeutic efficacy of antipsychotic medication is associated with weight change [7-12].

Nevertheless, weight change is a nonspecific physiological variable and changes in body weight alone are not sufficient to explain the potential mechanism of this relationship [13].

Previous studies have found that, compared with the healthy individuals, patients with schizophrenia have higher levels of serum lipids [5, 14-16]. Dyslipidemia has been demonstrated in untreated patients with schizophrenia $[17,18]$. These study findings revealed that lipid abnormalities are reflected by significant changes in the central nervous system as well as peripheral tissues, and serum lipoproteins may serve as a clue to the pathophysiology of schizophrenia. Several lines of evidence also suggest that dyslipidemia may be present in early stages of thedisease, even before treatment is initiated $[19,20]$. Furthermore, dyslipidemia has been found in patients with first-episode psychosis (FEP) and in drug-naïve patients with schizophrenia $[18,21,22]$. These studies indicated that changes in lipid metabolism occur 
during early development of the disease, which implies that the mechanism behind metabolic vulnerability may be related to the psychopathology of schizophrenia. We assumed that the changes in serum lipids, which may occur after an increase in body weight, can be used as a predictor for clinical improvement in patients treated with atypical antipsychotics.

It has been suggested that serum lipid concentration (total cholesterol and triglycerides) may be correlated with clinical effectiveness of clozapine [13,23,24]. The results show that an increase in either serum total cholesterol concentration or serum triglyceride concentration, or the combined effects of total cholesterol and triglycerides, are related to improvement in the clinical response of patients with schizophrenia receiving atypical antipsychotic medication. Lally et al. [23] reported that an increase in serum triglyceride level could predict clinical improvement in patients with schizophrenia taking clozapine. Interestingly, a recent study pointed out thatthe levels of triglycerides and cholesterol were negatively related to global functioning and that higher serum triglyceride levels were associated with more severe positive psychotic symptoms in schizophrenic patients treated with antipsychotics [25]. Further, a longitudinal study has reported that serum lipid levels are correlated with chronic symptom intensity in both acute andchronic stages of schizophrenia in patients receiving antipsychotics [16]. Recent meta-analyses found lower total cholesterol and LDL levels together with higher triglycerides in individuals with FEP [26-28]. This implies that dyslipidemia in patients with schizophrenia may not only result from the clinical use of antipsychotic medication but also be related to the illness itself.

Considering these inconsistencies, it is still uncertain whether lipid profiles are correlated with current symptom severity, and/or disease progression $[29,30]$. However, the inconsistencies may have resulted from the single post-treatment measurement used in most studies. The primary objective of this 12-week prospective, randomized and open label study was to investigate whether changes in serum lipid profiles were associated with clinical response in schizophrenic patients treated with atypical antipsychotics, using repeated measurements and considering time effects.

\section{Methods}

\section{Study design}

The study took place at Kaohsiung Armed Forces General Hospital in Kaohsiung, Taiwan. All study procedures were approved by the Institutional Review Board ofKaohsiung Armed Forces General Hospital, Taiwan (Protocol ID: T1-02). All participants provided written consent for all study procedures. This study was registered at clinicaltrials.gov (identifier NCT03730857) on Feb. 11, 2019, and followed CONSORT guidelines for a randomized trial (S1 Table).

\section{Participants}


Fig. 1 is a flowchart of the recruitment process. We recruited 101 eligible adult patients with schizophrenia who had had an acute psychotic episode and had been admitted to a psychiatric ward. We excluded 11 eligible patients because they refused to participate in the study. Ninety inpatients participated in this study and were randomly assigned to receive treatment with paliperidone $(n=30)$, risperidone $(n=30)$ or olanzapine $(n=30)$ in an allocation ratio of $1: 1: 1$. Participants were assigned using simple randomization procedures (computerized random numbers) to one of the three treatment groups. The randomization was conducted by a research assistant who was blinded to each patient's status. This study complied with basic principles of balancing the likelihood of harm, the effectiveness of monitoring, and the potential severity of risk. The participants were required to be willing and able to be hospitalized, and the duration of hospitalization was at least 1 month before follow-up as outpatients.

The inclusion criteria for this study were: (1) age 18-65 years; (2) meeting thediagnostic criteria for schizophrenia according to the Diagnostic and Structural Manual of Mental Disorders, Fourth Edition, Text Revision (DSM-IV-TR) [31]; (3) not having received long-acting antipsychotic injections in the preceding 6 months; and4) no major systemic illnesses based on physical examination and laboratory test results. The exclusion criteria were as follows: (1) history of clozapine treatment in the previous 6 months; (2) treatment with cholesterol or triglyceride-lowering medications; (3) substantial risks of suicide or violent behavior; (4) pregnancy or breastfeeding; (5) documented neurological or other medical disorder that could influence the function of the central nervous system; and (6) unstable or critical untreated medical illness.

\section{Trial procedures}

A triple therapy (paliperidone, risperidone and olanzapine) design was adopted in this study with a run-in period of 3 months. The patients were required to have discontinued all prior use of antipsychotics for at least 7 days before receiving one of the three atypical antipsychotics as a washout period.

The antipsychotic agents were administered with flexible dosing, which could be adjusted on the basis of the clinical judgment of the physicians in charge. The oral formulation was taken once daily and the recommended dosages for the three treatment groups were as follows: 6-12 mg paliperidone, 4-6 mg risperidone, and 10-20 mg olanzapine. Throughout the clinical trial, participants were permitted to use their concomitant medication continuously, including lorazepam (up to $6 \mathrm{mg} /$ day) for sleep disturbance or agitation and biperiden (up to $6 \mathrm{mg} / \mathrm{day}$ ) for treatment of extrapyramidal side effects. The use of other psychotropic agents and lipid-lowering medications was not allowed during the 3-month study.

\section{Measurements}

The initial evaluation included a comprehensive history comprising the patient's age at onset, duration of mental illness, educational level (years spent in school), family history of schizophrenia, and history of alcohol consumption and cigarette smoking. The clinical psychopathology of participants was assessed 
by Positive and Negative Syndrome Scale (PANSS) ratings. The PANSS total score ranges from 30 to 210, with higher scores indicating more severe psychopathology. The PANSS includes 30 items measuring positive symptoms, negative symptoms and general psychopathology [32]. The raters who assessed the PANSS did not know the name of the assigned drug. The participants underwent evaluation of clinical psychopathology and metabolic parameters, including serum lipid levels and body mass index (BMI) at initial assessment (baseline, day 0) and were followed up at weeks 4, 8 and 12. In this study, we used the BMI to examine the individual variability in weight change. The height of each participant was measured at baseline, their weight was measured at each clinical visit, and the two measurements were used to calculate BMI $\left(\mathrm{kg} / \mathrm{m}^{2}\right)$. Fasting morning blood samples for the laboratory investigation were initially drawn at baseline (after completion of drug washout), and then at weeks 4,8 and 12. Analyses of serum total cholesterol (TC), high-density lipoprotein (HDL) cholesterol, low-density lipoprotein (LDL) cholesterol and triglyceride (TG) were carried out by the standardized, automated, high throughput enzymatic analyses, which achieved within- and between-run coefficients of variation of $<5 \%$ [33].

\section{Statistical analysis}

All numeric variables are presented as mean \pm SD and categorical variables are summarized using frequencies and percentages. A series of repeated measures analyses of variance were then applied to evaluate continuous variables among the treatment groups. Post hoc analyses were conducted via Tukey tests.

We also applied generalized estimating equations (GEE) for repeated measures analysis and corrected within-subjectcorrelations, and the statistical model was developed to establish a prognostic prediction model for the therapeutic effect of treatment of schizophrenia by atypical antipsychotics across all four time points (day 0 and weeks 4, 8 and 12) [34]. The therapeutic effect was determined by the mean change in PANSS scores. The GEE method is often used for marginal regression analysis of longitudinal dataand other correlated response data, and is especially suitable for repeated measures studies. In addition to providing more efficient estimators of regression parameters, the main advantage of GEE is the comparison of correlated proportions using simulated data and coverage properties of the confidence interval. The GEE estimates average marginal effects and take into account the within-subject correlations by using an empirical covariance matrix.

We first used GEE linear regression models to evaluate adjusted associations between the lipid variables (total cholesterol, TG, HDL and LDL) and PANSS scores. The following baseline measures (see Table 1) were included as covariates in all adjusted analyses. We conducted a sequence of regression models adjusted for gender, age, age at onset, duration of mental illness (continuous), educational level (continuous), family history of schizophrenia (yes/no), history of alcohol consumption and cigarette smoking (yes/no), current type (categorical) and treatment dosage (continuous) of antipsychotics, and $\mathrm{BMI}$ (continuous). We then reduced this model by excluding covariates that did not predict the outcome with $p \leq 0.10$, or did not change the estimated association between lipid variables and PANSS score by $>$ 
$10 \%$ when removed from the model. The result of the final model is shown in Tables 3 and 4 . The time points (weeks) were entered as a within-subject factor in order to examine whether there was a significant time effect in the repeated measures analysis. The data analyses were performed using SPSS version

21.0 software (SPSS Inc., Chicago, IL, USA/IBM, New York, USA). Statistical significance was defined as $p$ $<0.05$ (two-sided).

\section{Results}

Ninety eligible patients (30 patients each in the paliperidone, risperidone and olanzapine groups) agreed to participate in this study initially. Twelve patients were lost from the study at week 8, and 14 at week 12 . Out of the 90 participants, 76 completed the 3-month study period (84.4\%). Failure to follow up was because the patients visited other hospitals (Fig. 1). No serious adverse effects were reported. Baseline demographic characteristics and clinical manifestations of the participants are presented in Tables 1 and 2. There were no significant differences in the demographic or baseline characteristics and mean PANSS total scores among the treatment groups.

The differences among the treatment groups in mean changes of PANSS total scores and lipid profiles over time are shown in Table 2 and Figure 2. All three groups showed a decrease in PANSS total score compared with baseline at weeks 4,8 and 12 . There were no significant differences in the levels of serum lipids among the three treatment groups at each time point.

In the GEE model, the PANSS total score and subscale scores (PANSS positive symptom score, negative symptom score and general psychopathological symptom score) were used as outcome variables while performing the appropriate statistical modeling to investigate the association of the lipid variables (collected over time) with the PANSS scores (also collected over time). The univariate and multivariate GEE analyses of the associations between the lipid variables and the PANSS scores, adjusted for baseline demographic and clinical data,are shown in Tables 3 and 4. The result of the GEE analysis showed that, within the participants tested, there was a significant time effect in the repeated measures analysis of PANSS ratings. We found that the increase in serum TC levels during 12 weeks of antipsychotic treatment was significantly associated with a reduction in PANSS total score $(\beta=-0.37, p=0.02)$ and positive symptom score $(\beta=-0.34, p=0.01)$ over time. This analysis revealed that there was no association between serum lipid changes and the PANSS negative symptom score or general psychopathology symptom score (data not shown). No other potential predictive factors were significantly associated with clinical treatment response. In terms of the relationship of serum lipid changes and psychopathology in schizophrenia, there was no significant difference among the three antipsychotic agents.

\section{Discussion}

The principal finding of this study was that, in patients with schizophrenia treated with atypical antipsychotics (olanzapine, risperidone or paliperidone), the increase in serum TC levels during 12 weeks of antipsychotic treatment was significantly associated with improvement in the clinical treatment 
response (i.e. reductions in PANSS total score and positive symptom score). No other potential predictors, including clinical demographic data,current type and dosage of antipsychotics, or BMI and other lipid profiles, were associated with ultimate response in this study.

These results demonstrate that higher TC levels are associated with greater improvement in clinical treatment response over time in schizophrenic patients treated with atypical antipsychotics. This is consistent with the findings of many previous studies on second-generation antipsychotics, which indicate that an increase in TC is associated with subsequent improvement of symptom intensity and functioning [13,35-37]. In contrast with previous studies that only measured the lipid profiles once, we measured them repeatedly and used the GEE approach to investigate the association between changes in serum TC level and psychopathology throughout the follow-up period. With regard to the metabolic effects in patients with schizophrenia treated with antipsychotics, a previous meta-analysis has reported that the increase in TC may be due to time-dependent exposure [38]. Some longitudinalstudies have shown that certain metabolic risk factors such as obesity and dyslipidemia may be present in the early stages of psychosis, prior to initiating treatment, and that the alteration in serum lipid profile is correlated with symptom intensity in schizophrenia $[16,19,20]$. The results of this study indicate that neither a reduction in PANSS general psychopathology nor a negative symptom score but a reduction in PANSS positive symptom score is associated with elevated serum total cholesterol levels.

Hyperlipidemia due to secondary causes is common and the etiology is important to recognize [39]. Currently, the most commonly used criterion for classifying overweight and obesity is BMI [40]. It has been found that the weight gain associated with antipsychotic treatment may be related to an improvement in psychosis in patients with schizophrenia [7-12]. Our findings suggest that an alteration in serum TC, independent of $\mathrm{BMI}$, is associated with a change in symptom severity during antipsychotic treatment.

Hyperlipidemia refers to elevated levels of TC, TG and LDL, and reduced HDL concentration.Prior research has shown that there is a potential correlation between an increase in serum TG levels and clinical improvement during clozapine treatment $[13,14,23]$. However, we did not observe similar results in the patients treated with paliperidone, risperidone or olanzapine. A previous meta-analysis showed that the prevalence of low HDL cholesterol was significantly higher among medicated multi-episode patients with schizophrenia than in those with FEP and in antipsychotic-naïve patients [41]. There was also a report of an association between an increase in HDL level and improvement in psychotic symptoms in patients with FEP after 1 year of antipsychotic treatment [42]. The association between different lipid profiles, such as HDL, and changes of psychopathology in patients with schizophrenia may need further study. Moreover, a recent systematic review and meta-analysis of 20 case-control studies found significant reductions in TC and LDL cholesterol levels in patients with FEP, suggesting that hypercholesterolemia in patients with chronic schizophrenia seems to be secondary and potentially modifiable [28]. Several studies have shown that patients with schizophrenia develop alterations in lipids at the onset of illness, indicating that such alterations should be regarded as an intrinsic factor contributing to schizophrenia [43-45]. There is also some evidence supporting a potential relationship between altered serum

Page $7 / 20$ 
cholesterol level and psychiatric symptoms in patients with mental illness, as well as those with schizophrenia [46-48].

Many studies have been conducted to understand the mechanisms underlying the multifaceted role of lipids in psychosis; for example, changes in cell membrane lipid profiles have been linked to treatment response $[17,49]$. These findings indicate that genetic and molecular mechanisms could be involved in the association between serum lipid dysregulation and the risk of developing schizophrenia [50]. Three major types of lipid that are abundant in the brain membrane are phospholipids, cholesterol and glycerophospholipids [51-53]. Anassociation between lipid profiles in serum and cell membranes and clinical symptoms in patients with schizophrenia has been demonstrated [25]. Accumulating evidence has also suggested a pivotal role for membrane-forming and signaling lipids of the brain in the pathogenesis of schizophrenia [54]. Furthermore, changes in the composition of membrane lipids in neuronal cells are correlated with neurotransmission, symptoms and behavior inschizophrenia [16]. Together, the associations between symptom severity and lipid levels suggest an important role of lipid biology in schizophrenia. Serum TC may be a potential biological predictor for treatment outcome in patients with schizophrenia undergoing drug therapy.

The strength of this study is that we conducted repeated measures of lipid levels (at time points 1-4) during the course of schizophrenia and studied their relationship with clinical symptom severity, which allowed us to investigate whether lipid profiles are associated with the pathogenesis of schizophrenia. This has not been done before in similar studies. However, the present study had some limitations that had to be taken into account before forming a conclusion. First, life-style factors, including daily dietary intake and exercise, are also recognized to influence lipid parameters, but these characteristics of the patients in this study were not controlled. Second, the small sample size in the groups given the different drugs may have increased the type I error rate. Third, identifying more substantial factors to correlate the therapy response with other factors (such as plasma levels of antipsychotic medication) in specific subgroups of patients may provide a rationale for this observation, and explain the drug response.

\section{Conclusion}

Serum TC, independent from BMI, may be used as one of the predictive indicators for treatment efficacy in patients with schizophrenia treated with paliperidone, risperidone or olanzapine. The findings of this study suggest that more research is warranted to determine the details of the underlying mechanisms and to elucidate the relationships between lipid biology and the pathophysiology of schizophrenia.

\section{Supporting Information}

S1 Table. CONSORT checklist. CONSORT 2010 checklist of information to include when reporting a randomized trial.

(DOCX) 


\section{Abbreviations}

DSM-IV-TR: Diagnostic and Structural Manual of Mental Disorders, Fourth Edition, Text Revision

PANSS: the Positive and Negative Syndrome Scale

GEE: generalized estimating equation

BMI: body mass index

TC: total cholesterol

HDL: high-density lipoprotein cholesterol

\section{LDL: low-density lipoprotein cholesterol}

\section{TG: triglyceride}

FEP: first-episode psychosis

\section{Declarations}

\section{Ethics approval and consent to participate}

This study was approved by the Institutional Review Board of Kaohsiung Armed Forces General Hospital, Taiwan. All participants provided written consent.

Consent to publish

Not applicable.

\section{Availability of data and materials}

The datasets used and/or analyzed in the current study are available from the corresponding author on reasonable request.

\section{Competing interests}

The authors declare that they have no competing interests. 


\section{Funding}

This study was supported financially by the Medical Affairs Bureau, Ministry of National Defense, Taiwan. The corresponding author had full access to all data in the study and had final responsibility for the decision to submit for publication. The funding bodies of this study had no rolein the design of the study, the collection, analysis, and interpretation of data, or in writing the manuscript.

\section{Author's Contributions}

All authors had full access to all of the data in the study and take responsibility for the integrity of the data and the accuracy of the data analysis. YL contributed to the data collection and analyses, and writing of the manuscript. FW and MH supervised the execution and collection of data, participated in the development of the protocol, performed the final data analyses, and edited the manuscript. CC and KP contributed to the statistics advice, and made comments on and revised the manuscript.

\section{Acknowledgements}

The efforts of the medical staff in collecting and managing the clinical data on the participants are acknowledged.

\section{Author's Information}

${ }^{1}$ Department of Biological Sciences, National Sun Yat-sen University, Kaohsiung, Taiwan. ${ }^{2}$ Department of Psychiatry, Taipei City Psychiatric Center, Taipei City Hospital, Taipei, Taiwan. ${ }^{3}$ Department of Psychiatry, School of Medicine, College of Medicine, Taipei Medical University, Taipei, Taiwan. ${ }^{4}$ Instituteof Biomedical Sciences, National Sun Yat-Sen University, 70 Lienhai Rd, Kaohsiung 80424, Taiwan, Republic of China.

${ }^{5}$ Calo Psychiatric Center, No.12-200, Jinhua Rd., Xinpi Township, Pingtung County 925, Taiwan.

${ }^{6}$ Graduate Institute of Medical Sciences, National Defense Medical University, Taipei, Taiwan.

\section{References}

\section{References}

- Bak M, Fransen A, Janssen J, van Os J, Drukker M. Almost all antipsychotics result in weight gain: a meta-analysis. PloS One. 2014; 9: e94112.

- Chaggar PS, Shaw SM, Williams SG. Effect of antipsychotic medications on glucose and lipid levels. Journal of clinical pharmacology. 2011; 51: 631-638.

- Jeon SW, Kim YK. Unresolved Issues for Utilization of Atypical Antipsychotics in Schizophrenia: Antipsychotic Polypharmacy and Metabolic Syndrome. Int J Mol Sci. 2017;18: 2174-2189. 
- Papanastasiou E. Interventions for the metabolic syndrome in schizophrenia: a review. Ther Adv Endocrinol Metab. 2012;3:141-62.

- Paton C, Esop R, Young C, Taylor D. Obesity, dyslipidaemias and smoking in inpatient population treated with antipsychotic drugs. Acta Psychiatr Scand 2004; 110: 299-305.

- Zhang Y, Liu Y, Su Y, You Y, Ma Y, Yang G, Song Y, Liu X, Wang M, Zhang L, Kou C. The metabolic side effects of 12 antipsychotic drugs used for the treatment of schizophrenia on glucose: a network meta-analysis. BMC psychiatry. 2017; 17: 373.

- Czobor P, Volavka J, Sheitman B, Lindenmayer JP, Citrome L, McEvoy J, Cooper TB, Chakos M, Lieberman JA. Antipsychotic-induced weight gain and therapeutic response: a differential association. J Clin Psychopharmacol. 2002; 22: 244-251.

- Hermes E, Nasrallah H, Davis V, Meyer J, McEvoy J, Goff D, Davis S, Stroup TS, Swartz M, Lieberman $\mathrm{J}$, Rosenheck $\mathrm{R}$. The association between weight change and symptom reduction in the CATIE schizophrenia trial. Schizophr Res. 2011;128: 166-170.

- Lamberti JS, Bellnier T, Schwarzkopf SB. Weight gain among schizophrenic patients treated with clozapine. Am J Psychiatry. 1992; 149: 689-690.

- Lane HY, Chang YC, Cheng YC, Liu GC, Lin XR, Chang WH. Effects of patient demographics, risperidone dosage, and clinical outcome on body weight in acutely exacerbated schizophrenia. $J$ Clin Psychiatry. 2003; 64: 316-320.

- Meltzer HY, Perry E, Jayathilake K. Clozapine-induced weight gain predicts improvement in psychopathology. Schizophr Res. 2003; 59: 19-27.

- Sharma E, Rao NP, Venkatasubramanian G. Association between antipsychotic-induced metabolic side-effects and clinical improvement: a review on the evidence for metabolic threshold: author's response. Asian J Psychiatr. 2014;11: 76.

- Procyshyn RM, Wasan KM, Thornton AE, Barr AM, Chen EY, Pomarol-Clotet E, Stip E, Williams R, Macewan GW, Birmingham CL, Honer WG. Changes in serum lipids, independent of weight, are associated with changes in symptoms during long-term clozapine treatment. J Psychiatry Neurosci. 2007; 32: 331-338.

- Pande S, Procyshyn RM, Nazerali M, Attwood D, Chow K. Do triglycerides modulate the effectiveness of clozapine? Int Clin Psychopharmacol. 2002;17: 197-199.

- Saari K, Jokelainen J, Veijola J, Koponen H, Jones PB, Savolainen M, Järvelin MR, Lauren L, Isohanni $M$, Lindeman S. Serum lipids in schizophrenia and other functional psychoses: a general population northern Finland 1966 birth cohort survey. Acta Psychiatr Scand. 2004;110: 279-285.

- Solberg DK, Bentsen H, Refsum H, Andreassen OA. Lipid profiles in schizophrenia associated with clinical traits: a five year follow-up study. BMC Psychiatry. 2016; 16: 299.

- Kaddurah-Daouk R, McEvoy J, Baillie R, Zhu H, Yao KJ, Nimgaonkar VL, Buckley PF, Keshavan MS, Georgiades A, Nasrallah HA. Impaired plasmalogens in patients with schizophrenia. Psychiatry Res. 2012; 198: 347-352. 
- Schwarz E, Prabakaran S, Whitfield P, Major H, Leweke FM, Koethe D, McKenna P, Bahn S. High throughput lipidomic profiling of schizophrenia and bipolar disorder brain tissue reveals alterations of free fatty acids, phosphatidylcholines, and ceramides. J Proteome Res. 2008;7: 4266-4277.

- Fenton WS, Hibbeln J, Knable M. Essential fatty acids, lipid membrane abnormalities, and the diagnosis and treatment of schizophrenia. Biol Psychiatry. 2000; 47: 8-21.

- McEvoy J, Baillie RA, Zhu H, Buckley P, Keshavan MS, Nasrallah HA, Dougherty GG, Yao JK, Kaddurah-Daouk R. Lipidomics reveals early metabolic changes in subjects with schizophrenia: effects of atypical antipsychotics. PLoS One. 2013; 8: e68717.

- Thakore JH. Metabolic disturbance in first-episode schizophrenia. Br J Psychiatry. 2004; Suppl. 47: S76-S79.

- Verma SK, Subramaniam M, Liew A, Poon LY. Metabolic risk factors in drug-naive patients with firstepisode psychosis. J Clin Psychiatry. 2009; 70: 997-1000.

- Lally J, Gallagher A, Bainbridge E, Avalos G, Ahmed M, McDonald C. Increases in triglyceride levels are associated with clinical response to clozapine treatment. J Psychopharmacol. 2013;27: 401403.

- Procyshyn RM, Honer WG, Barr AM. Do serum lipids predict response to clozapine treatment? J Psychiatry Neurosci. 2009; 34: 168.

- Solberg DK, Bentsen H, Refsum H, Andreassen OA. Association between serum lipids and membrane fatty acids and clinical characteristics in patients with schizophrenia. Acta psychiatrica Scandinavica. 2015;132: 293-300.

- Misiak B, Stanczykiewicz B, Laczmanski L, Frydecka D. Lipid profile disturbances in antipsychoticnaive patients with first-episode non-affective psychosis: A systematic review and meta-analysis. Schizophr Res. 2017; 190: 18-27.

- Perry BI, Mclntosh G, Weich S, Singh S, Rees K. The association between first-episode psychosis and abnormal glycaemic control: systematic review and meta-analysis. Lancet Psychiatry. 2016; 3: 1049-1058.

- Pillinger T, Beck K, Stubbs B, Howes OD. Cholesterol and triglyceride levels in first-episode psychosis: systematic review and meta-analysis. Br J Psychiatry. 2017; 211: 339-349.

- Montesinos-Rueda L, Canete-Crespillo J, Palma-Sevillano C, Gine-Serven E. Erythrocyte membrane polyunsaturated fatty acid (pufa) levels in a sample of patients with schizophrenia and relation with clinical and progression variables. Actas Esp Psiquiatr. 2015; 43: 170-176.

- Van der Kemp WJ, Klomp DW, Kahn RS, Luijten PR, Hulshoff Pol HE. A metaanalysis of the polyunsaturated fatty acid composition of erythrocyte membranes in schizophrenia. Schizophr Res. 2012; 141: 153-161.

- American Psychiatric Association. Diagnostic and statistical manual of mental disorders (4th ed., text rev.). Washington DC: American Psychiatric Association; 2000.

- Lindenmayer JP, Czobor P, Volavka J, Lieberman JA, Citrome L, Sheitman B, McEvoy JP, Cooper TB, Chakos M. Effects of atypical antipsychotics on the syndromal profile in treatment-resistant 
schizophrenia. J Clin Psychiatry. 2004; 65: 551-556.

- McNamara JR, Schaefer EJ. Automated enzymatic standardized lipid analyses for plasma and lipoprotein fractions. Clin Chim Acta. 1987; 166: 1-8.

- Zeger SL, Liang KY. Longitudinal data analysis for discrete and continuous outcomes. Biometrics. 1986; 42: 121-130.

- Boston PF, Dursun SM, Zafar R, Reveley MA. Serum cholesterol and treatment-resistance in schizophrenia. Biol Psychiatry. 1996; 40: 542-543.

- Chen SF, Hu TM, Lan TH, Chiu HJ, Sheen LY, Loh EW. Severity of psychosis syndrome and change of metabolic abnormality in chronic schizophrenia patients: severe negative syndrome may be related to a distinct lipid pathophysiology. Eur Psychiatry. 2014; 29: 167-171.

- Krakowski M, Czobor P. Cholesterol and cognition in schizophrenia: a double-blind study of patients randomized to clozapine, olanzapine and haloperidol. Schizophr Res. 2011; 130: 27-33.

- Moteshafi H, Zhornitsky S, Brunelle S, Stip E. Comparing tolerability of olanzapine in schizophrenia and affective disorders: a meta-analysis. Drug Saf. 2012; 35: 819-836.

- Tonstad S, Despres JP. Treatment of lipid disorders in obesity. Expert Rev Cardiovasc Ther. 2011; 9: 1069-1080.

- Keke LM, Samouda H, Jacobs J, di Pompeo C, Lemdani M, Hubert H, Zitouni D, Guinhouya BC. Body mass index and childhood obesity classification systems: A comparison of the French, International Obesity Task Force (IOTF) and World Health Organization (WHO) references. Rev Epidemiol Sante Publique. 2015; 63: 173-182.

- Vancampfort D, Wampers M, Mitchell AJ, Correll CU, De Herdt A, Probst M, De Hert M. A metaanalysis of cardio-metabolic abnormalities in drug naïve, first-episode and multi-episode patients with schizophrenia versus general population controls. World Psychiatry. 2013; 12: 240-250.

- Gjerde PB, Dieset I, Simonsen C, Hoseth EZ, Iversen T, Lagerberg TV, Lyngstad SH, Mørch RH, Skrede $S$, Andreassen OA, Melle I, Steen VM. Increase in serum HDL level is associated with less negative symptoms after one year of antipsychotic treatment in first-episode psychosis. Schizophr Res. 2018; 197: 253-260.

- Basoglu C, Oner O, Gunes C, Semiz UB, Ates AM, Algul A, Ebrinc S, Cetin M, Ozcan O, Ipcioglu O. Plasma orexin A, ghrelin, cholecystokinin, visfatin, leptin and agouti-related protein levels during 6week olanzapine treatment in first-episode male patients with psychosis. Int Clin Psychopharmacol. 2010; 25: 165-171.

- Enez Darcin A, Yalcin Cavus S, Dilbaz N, Kaya H, Dogan E. Metabolic syndrome in drug-naïve and drug-free patients with schizophrenia and in their siblings. Schizophr Res. 2015; 166: 201-206.

- Saddichha S, Manjunatha N, Ameen S, Akhtar S. Metabolic syndrome in first episode schizophrenia a randomized double-blind controlled, short-term prospective study. Schizophr Res. 2008; 101: 266272.

- Ainiyet B, Rybakowski JK. Suicidal behavior in schizophrenia may be related to low lipid levels. Med Sci Monit. 2014; 20: 1486-1490. 
- Mensi R, Messaoud A, Mhallah A, Azizi I, Salah WH, Douki W, Najjar MF, Gaha L. The association between altered lipid profile and suicide attempt among Tunisian patients with schizophrenia. Ann Gen Psychiatry. 2016; 15: 36.

- Troisi A. Cholesterol in coronary heart disease and psychiatric disorders: same or opposite effects on morbidity risk. Neurosci Biobehav Rev. 2009; 33: 125-132.

- Tessier C, Sweers K, Frajerman A, Bergaoui H, Ferreri F, Delva C, Lapidus N, Lamaziere A, Roiser JP, De Hert M, Nuss P. Membrane lipidomics in schizophrenia patients: a correlational study with clinical and cognitive manifestations. Transl Psychiatry. 2016; 6: e906.

- Andreassen OA, Djurovic S, Thompson WK, Schork AJ, Kendler KS, O’Donovan MC, Rujescu D, Werge T, van de Bunt M, Morris AP, McCarthy MI, Roddey JC, McEvoy LK, Desikan RS, Dale AM. Improved detection of common variants associated with schizophrenia by leveraging pleiotropy with cardiovascular-disease risk factors. Am J Hum Genet. 2013; 92: 197-209.

- Jackson SN, Wang HYJ, Woods AS. Direct profiling of lipid distribution in brain tissue using MALDITOFMS. Anal Chem. 2005; 77: 4523-4527.

- Jackson SN, Wang HYJ, Woods AS. In situ structural characterization of glycerophospholipids and sulfatides in brain tissue using MALDI-MS/MS. J Am Soc Mass Spectrom. 2007; 1: 17-26.

- Jain M, Ngoy S, Sheth SA, Swanson RA, Rhee EP, Liao R, Clish CB, Mootha VK, Nilsson R. A systematic survey of lipids across mouse tissues. Am J Physiol Endocrinol Metab. 2014; 306: E854E868.

- Schneider M, Levant B, Reichel M, Gulbins E, Kornhuber J, Muller CP. Lipids in psychiatric disorders and preventive medicine. Neurosci Biobehav Rev. 2017; 76: 336-362.

\section{Tables}


Table 1. Demographic and clinical characteristics of patients with schizophrenia treated with paliperidone, risperidone or olanzapine

\begin{tabular}{|c|c|c|c|c|}
\hline & $\begin{array}{l}\text { Paliperidone } \\
\qquad(n=30)\end{array}$ & $\begin{array}{l}\text { Risperidone } \\
\qquad(n=30)\end{array}$ & $\begin{array}{l}\text { Olanzapine } \\
\qquad(n=30)\end{array}$ & $p$ \\
\hline Sex, N(\%) & & & & 0.92 \\
\hline Male & $16(53.3)$ & $15(53.5)$ & $17(56.7)$ & \\
\hline Female & $14(46.7)$ & $15(46.4)$ & $13(43.3)$ & \\
\hline Age, mean \pm SD (years) & $36.21 \pm 11.27$ & $35.04 \pm 9.85$ & $35.60 \pm 11.26$ & 0.78 \\
\hline Age at onset, mean $\pm \mathrm{SD}$ (years) & $26.17 \pm 6.60$ & $24.71 \pm 4.81$ & $26.70 \pm 8.46$ & 0.49 \\
\hline $\begin{array}{l}\text { Duration of illness, mean } \pm S D \\
\text { (years) }\end{array}$ & $10.00 \pm 7.54$ & $7.24 \pm 6.92$ & $8.96 \pm 9.72$ & 0.72 \\
\hline $\begin{array}{l}\text { Educational level, mean } \pm \text { SD } \\
\text { (years) }\end{array}$ & $11.03 \pm 3.06$ & $12.39 \pm 2.46$ & $11.91 \pm 3.81$ & 0.14 \\
\hline $\mathrm{BMI}$, mean $\pm \mathrm{SD}\left(\mathrm{kg} / \mathrm{m}^{2}\right)$ & $24.58 \pm 4.64$ & $24.69 \pm 4.15$ & $25.01 \pm 5.03$ & 0.45 \\
\hline Alcohol history, n (\%) & $5 / 25(16.7)$ & $4 / 26(14.3)$ & $6 / 24(17.0)$ & 0.95 \\
\hline Smoking history, n (\%) & $15 / 15(50.0)$ & $16 / 14(57.1)$ & $14 / 16(43.4)$ & 0.39 \\
\hline $\begin{array}{l}\text { Family history of schizophrenia, } \\
\text { n (\%) }\end{array}$ & $9 / 21(30.0)$ & $7 / 23(25.0)$ & $8 / 22(32.1)$ & 0.70 \\
\hline $\mathrm{TC}$, mean $\pm \mathrm{SD}(\mathrm{mg} / \mathrm{dL})$ & $145.77 \pm 83.61$ & $139.39 \pm 87.59$ & $153.57 \pm 85.41$ & 0.055 \\
\hline $\begin{array}{l}\mathrm{TG}, \text { mean } \pm \mathrm{SD} \\
(\mathrm{mg} / \mathrm{dL})\end{array}$ & $169.53 \pm 79.09$ & $167.61 \pm 70.84$ & $175.65 \pm 87.01$ & 0.11 \\
\hline $\mathrm{HDL}$, mean $\pm \mathrm{SD}(\mathrm{mg} / \mathrm{dL})$ & $45.83 \pm 14.66$ & $44.64 \pm 12.18$ & $48.87 \pm 19.96$ & 0.46 \\
\hline $\mathrm{LDL}$, mean $\pm \mathrm{SD}(\mathrm{mg} / \mathrm{dL})$ & $112.10 \pm 37.44$ & $104.25 \pm 28.16$ & $119.26 \pm 41.03$ & 0.22 \\
\hline
\end{tabular}

Abbreviations: BMI: body mass index; HDL: high-density lipoprotein; LDL: low-density lipoprotein; TC: total cholesterol; TG; triglyceride. 
Table 2. Change in mean PANSS total scores over time and comparative analysis among groups

\begin{tabular}{|c|c|c|c|c|c|c|c|c|}
\hline \multirow{2}{*}{$\begin{array}{l}\text { Mean PANSS total } \\
\text { scores }\end{array}$} & \multirow{2}{*}{$\begin{array}{l}\text { Group } \\
\text { variable }\end{array}$} & \multirow[t]{2}{*}{$\mathbf{n}$} & \multirow[t]{2}{*}{ Mean (SD) } & \multirow[t]{2}{*}{ SE } & \multicolumn{2}{|c|}{$95 \%$ CI for mean } & \multirow[b]{2}{*}{ F } & \multirow[b]{2}{*}{$P$} \\
\hline & & & & & Lower bounc & $\begin{array}{l}\text { Upper } \\
\text { bound }\end{array}$ & & \\
\hline Mean PANSS & Paliperidone & 30 & 84.67(22.99) & 4.20 & 76.08 & 93.25 & & \\
\hline \multirow{3}{*}{$\begin{array}{l}\text { total scores at } \\
\text { baseline }\end{array}$} & Risperidone & 30 & $94.39(23.40)$ & 4.42 & 85.32 & 103.46 & & \\
\hline & Olanzapine & 30 & $89.85(22.29)$ & 3.06 & 83.70 & 95.99 & & \\
\hline & Total & 90 & $89.59(22.83)$ & 2.17 & 85.30 & 93.89 & 1.33 & 0.27 \\
\hline \multirow[t]{2}{*}{ Mean PANSS } & Paliperidone & 30 & $74.19(19.01)$ & 3.66 & 66.66 & 81.71 & & \\
\hline & Risperidone & 30 & $84.24(19.87)$ & 3.98 & 76.04 & 92.44 & & \\
\hline \multirow{2}{*}{$\begin{array}{l}\text { total scores at Week } \\
4\end{array}$} & Olanzapine & 30 & $70.22(23.62)$ & 3.88 & 62.34 & 78.09 & & \\
\hline & Total & 90 & $75.36(21.83)$ & 2.31 & 70.76 & 79.96 & 3.30 & 0.04 \\
\hline \multirow{4}{*}{$\begin{array}{l}\text { Mean PANSS } \\
\text { total scores at Week } \\
8\end{array}$} & Paliperidone & 24 & $70.42(18.04)$ & 3.68 & 62.80 & 78.03 & & \\
\hline & Risperidone & 25 & $82.60(18.20)$ & 3.64 & 75.09 & 90.11 & & \\
\hline & Olanzapine & 29 & $68.94(24.43)$ & 4.32 & 60.13 & 77.74 & & \\
\hline & Total & 78 & $73.59(21.47)$ & 2.39 & 68.84 & 78.34 & 3.41 & 0.04 \\
\hline \multirow{4}{*}{$\begin{array}{l}\text { Mean PANSS } \\
\text { total scores at Week } \\
12\end{array}$} & Paliperidone & 23 & $72.17(19.90)$ & 4.69 & 62.27 & 82.06 & & \\
\hline & Risperidone & 25 & $79.20(19.26)$ & 3.85 & 71.25 & 87.15 & & \\
\hline & Olanzapine & 28 & $67.11(18.22)$ & 3.44 & 60.04 & 74.17 & & \\
\hline & Total & 76 & 72.65(19.47) & 2.31 & 68.04 & 77.26 & 2.68 & 0.08 \\
\hline
\end{tabular}

CI: confidence interval; PANSS: Positive and Negative Syndrome Scale; SD: standard deviation; SE: standard error. ${ }^{*} p$ $<0.05$ statistically significant. 
Table 3. Generalized estimating equation results for association of serum lipid profiles with PANSS total score and change in PANSS total score over time

\begin{tabular}{|l|c|c|c|c}
\hline Independent variable & $\boldsymbol{\beta}$ & SE & $95 \%$ CI & $p$ \\
\hline TG & -0.01 & 0.03 & -0.05 to 0.07 & 0.69 \\
\hline TC & -0.03 & 0.02 & -0.01 to 0.02 & 0.17 \\
\hline HDL & 0.06 & 0.11 & -0.25 to 0.18 & 0.77 \\
\hline LDL & -0.02 & 0.05 & -0.12 to 0.08 & 0.67 \\
\hline Time (week) & -2.16 & 0.89 & -3.90 to 0.42 & 0.11 \\
\hline TGxtime & -0.03 & 0.03 & -0.04 to 0.03 & 0.28 \\
\hline TCxtime & -0.37 & 0.04 & -0.44 to -0.18 & 0.02 \\
\hline HDLxtime & 0.07 & 0.12 & -0.17 to 0.31 & 0.56 \\
\hline LDLxtime & -0.09 & 0.07 & -0.10 to 0.22 & 0.16 \\
\hline
\end{tabular}

Dependent variable: PANSS total score.

Abbreviations: CI: confidence interval; $\beta$ : regression coefficient; HDL: high-density lipoprotein; LDL: lowdensity lipoprotein; PANSS: Positive and Negative Syndrome Scale; SE: standard error; TC: total cholesterol; TG: triglyceride. 
ble 4. Generalized estimating equation results for association of serum lipid profiles th PANSS positive symptom score and change in PANSS positive symptom score over 10

\begin{tabular}{|l|c|c|c|c|}
\hline lependent variable & $\boldsymbol{\beta}$ & SE & $95 \%$ CI & $p$ \\
\hline i & -0.02 & 0.01 & -0.04 to 0.01 & 0.82 \\
\hline JL & -0.04 & 0.01 & -0.02 to 0.01 & 0.19 \\
\hline IL & 0.05 & 0.04 & -0.03 to 0.13 & 0.28 \\
\hline ne (weeks) & -0.04 & 0.24 & -0.09 to 0.04 & 0.47 \\
\hline ixtime & -0.20 & 0.74 & -1.26 to 1.65 & 0.79 \\
\hline :xtime & 0.13 & 0.03 & -0.02 to 0.02 & 0.74 \\
\hline JLxtime & -0.34 & 0.02 & -0.43 to -0.11 & 0.01 \\
\hline LLxtime & 0.01 & 0.11 & -0.02 to 0.02 & 0.36 \\
\hline
\end{tabular}

Jendent variable: PANSS positive symptom score.

Jreviations: CI: confidence interval; $\beta$ : regression coefficient; HDL: high-density lipoprotein; LDL: low1sity lipoprotein; PANSS: Positive and Negative Syndrome Scale; SE: standard error; TC: total lesterol; TG: triglyceride.

Figures 


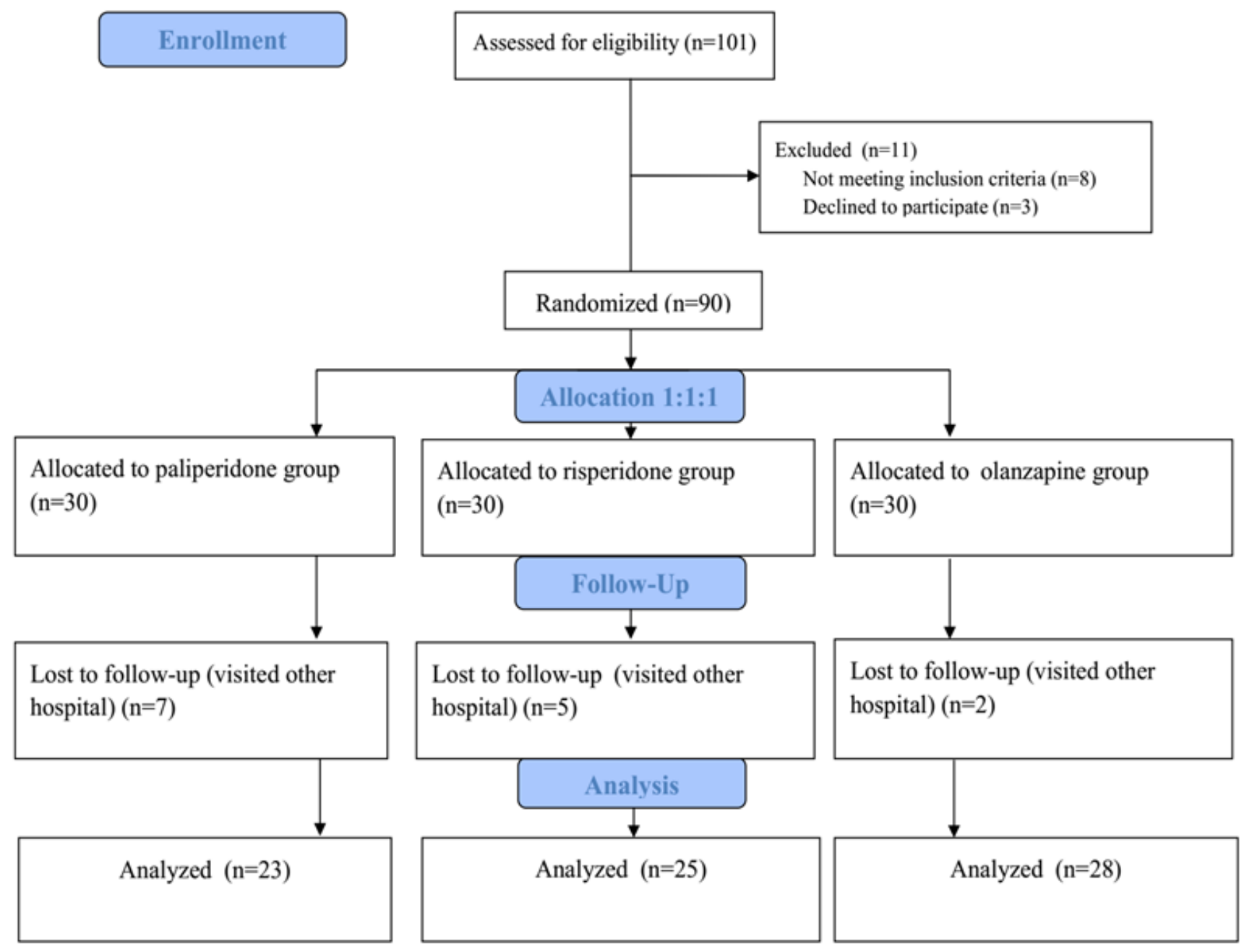

\section{Figure 1}

Flow chart of participants through the study 

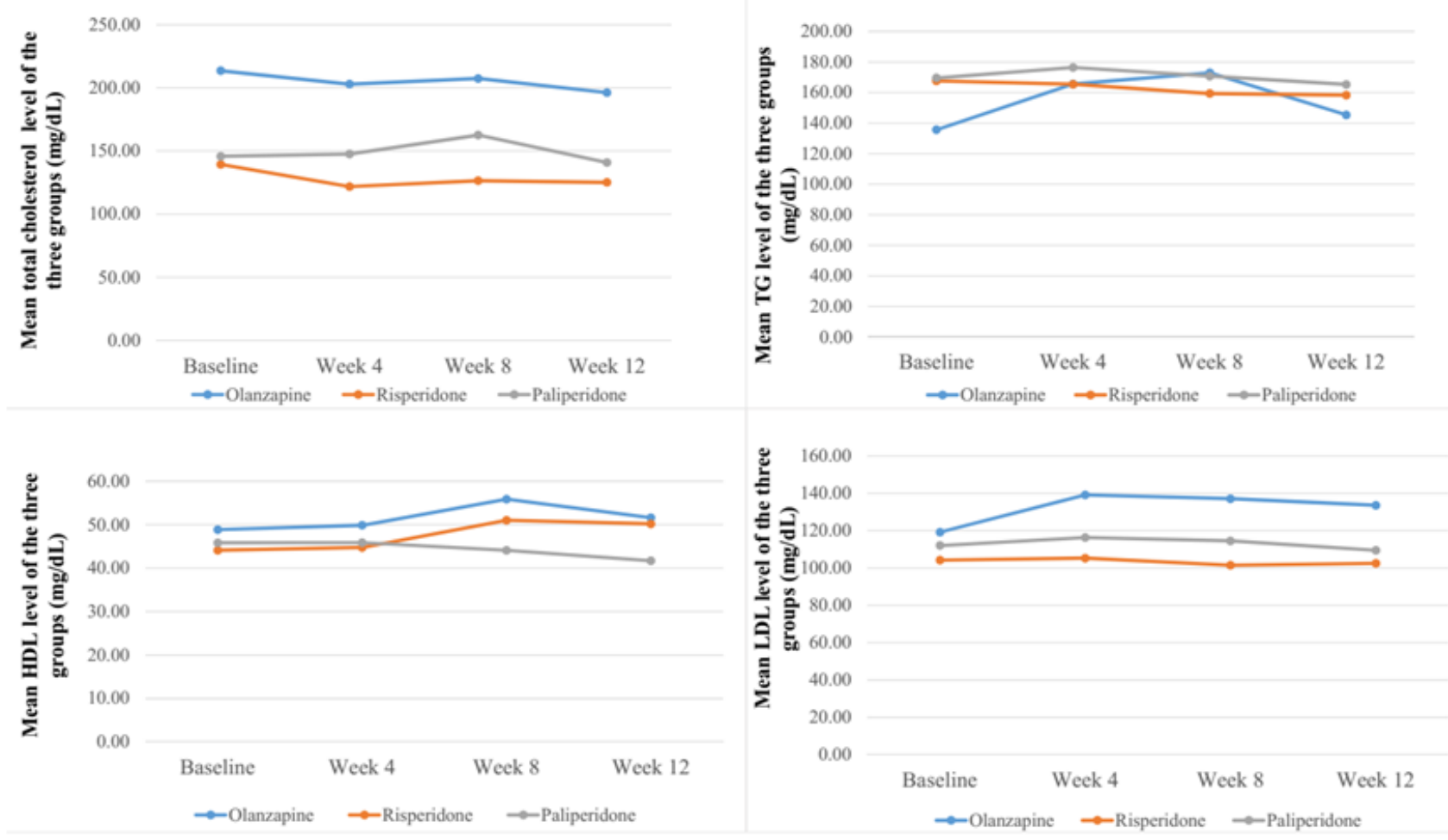

Figure 2

Comparison of the mean lipid levels of patients with schizophrenia in the three groups

\section{Supplementary Files}

This is a list of supplementary files associated with this preprint. Click to download.

- S1Table.CONSORTchecklist.doc 